\title{
Left Atrial Volume Index in Patients with Dilated Cardiomyopathy-Correlation with Left Ventricular Function
}

\author{
Stanley George \\ Department of Cardiology, Pariyaram Medical College, Kannur, Kerala 670503, India \\ Email: s4stanley@gmail.com
}

How to cite this paper: George, S. (2016) Left Atrial Volume Index in Patients with Dilated Cardiomyopathy-Correlation with Left Ventricular Function. World Journal or Cardiovascular Diseases, 6, 312-319. http://dx.doi.org/10.4236/wjcd.2016.69035

Received: September 9, 2016 Accepted: September 24, 2016 Published: September 27, 2016

Copyright $\odot 2016$ by author and Scientific Research Publishing Inc. This work is licensed under the Creative Commons Attribution International License (CC BY 4.0).

http://creativecommons.org/licenses/by/4.0/ (c) (i) Open Access

\begin{abstract}
Background: The aim of this study was to determine the relation of left atrial (LA) volume and LA volume index with left ventricular function and to determine the association of duration of symptoms and left atrial volume index in patients with dilated cardiomyopathy. Materials and Methods: This was an observational, single centre study conducted in India. A total of 50 patients who were admitted to department of cardiology from July, 2008 to February, 2009 with diagnosis of dilated cardiomyopathy and an ejection fraction of $<40 \%$ were included. Results: Of the 50 patients, $34(68 \%)$ were males. $27(54 \%)$ patients were in NYHA class II and 23 (46\%) patients were in NYHA class III. LA volume was found to be $\geq 40 \mathrm{ml}$ in all patients. LV function and LA volume were found to be correlated $(\mathrm{r}=-0.789, \mathrm{p}<$ $0.01)$. Similarly, there was a correlation between LV function and LA volume index ( $\mathrm{r}$ $=-0.826, \mathrm{p}<0.01)$. There was no correlation between LA volume index and duration of symptoms $(\mathrm{r}=0.04)$. Conclusion: It can be concluded that there is a strong inverse correlation between LA volume and left ventricular function and also between LA volume index and left ventricular function. The patients with NYHA class III were having larger left atrial volume than those with NYHA class II. Moreover, the duration of symptoms has no correlation with left atrial volume index.
\end{abstract}

\section{Keywords}

Ejection Fraction, Dilated Cardiomyopathy, Left Atrial Volume Index, Left Ventricular Function

\section{Introduction}

Dilated cardiomyopathy is a syndrome characterized by enlargement of cardiac chambers and compromised systolic function of one or both ventricles [1]. It is largely asso- 
ciated with poor prognosis. Substantial variability has been reflected in the clinical course and the morphologic and hemodynamic features of the patients [2].

In patients with dilated cardiomyopathy, left atrial (LA) sizes have varied largely [3] [4]. The prognostic impact of this observation had been scrutinized in the Studies Of Left Ventricular Dysfunction (SOLVD) population [5]. Patients with a reduced left ventricular (LV) ejection fraction (EF) had an escalated risk proportional to the increase in the size of LA [6]. The eminent contributing factors of LA volume are degree of ventricular remodeling, mitral regurgitation (MR) and the presence of atrial fibrillation (AF) [7]. Yet, it is indistinct whether the prognostic power of the LA enlargement might be the result of LV diastolic dysfunction or the presence of MR or AF; such that, all of these pathophysiologic variables influence both enlarging the atrial chamber and prognosis in patients with a decreased EF [6].

It has been demonstrated that the size of the LA is better described by volume rather than diameter. Lester et al. [8] suggested that LA may become less spherical as it enlarges and thus, that LA volume may be a more sensitive index of LA enlargement. Though atrial enlargement has been associated with an augmented mortality rate [9], the pathophysiologic determinants of atrial size have not been routinely examined, specifically in patients with ventricular diseases. Thus, the aim of this study was to determine the relation of left atrial volume and left atrial volume index with left ventricular function and to determine the association of duration of symptoms and left atrial volume index in patients with dilated cardiomyopathy.

\section{Materials and Methods}

\subsection{Study Design and Patient Population}

This was an observational, single centre study in which a total of 50 consecutive patients admitted to department of cardiology at a centre in India, from July, 2008 to February, 2009 were included. The inclusion criteria constituted of patients with diagnosis of dilated cardiomyopathy and an ejection fraction of $<40 \%$.

Patients with organic mitral or aortic valve disease and those with incidence of a recent myocardial infarction ( $<6$ months) of any type were excluded. All participants gave their informed consent and the study complies with Declaration of Helsinki and study protocol was approved by Institutional Ethics Committee.

\subsection{Study Procedure}

A detailed history and physical examination was done in all patients. A standard 12lead electrocardiogram and chest X-ray was taken. Echocardiographic evaluation was done with Philips HD 11 XE machine, with Doppler facilities. From the standard parasternal long axis view, left ventricular dimension, left atrial size and ejection fraction were measured. Both apical 4 chamber and 2 chamber views were obtained.

The area-length method was used for LA volume measurement, by $(0.85 \times \mathrm{A} 1 \times$ A2)/L formula [10]. Here, A1 is the area in apical four chamber view; A2 is the area in apical two chamber view; $L$ is the linear dimension from the centre of the mitral annu- 
lus to the superior border of the chamber. Left atrial volume index was calculated by left atrial volume/body surface area. Body surface area was determined from body weight and height. The LA volume index of $22 \pm 6 \mathrm{ml} / \mathrm{m}^{2}$ was considered normal; 29 $33 \mathrm{ml} / \mathrm{m}^{2}$ implied mild elevation of LA volume index; $34-39 \mathrm{ml} / \mathrm{m}^{2}$ implied moderate elevation of LA volume index; $>40 \mathrm{ml} / \mathrm{m}^{2}$ implied severe elevation of LA volume index [11].

Mitral regurgitation (MR) was semi-quantitatively assessed by colour flow Doppler echocardiography and regurgitation grades were determined. Grade for MR were-0 for no MR; 1 for trace MR; 2 for mild MR; 3 for moderate MR; 4 for severe MR.

Chest X-ray was examined and LA enlargement was noted in three grades. Grade 1LA border is inside right atrial (RA) border; Grade 2-LA border approximate with RA border; Grade 3-LA border beyond RA border. ECG was analysed and Macruz index was calculated.

\subsection{Statistical Analysis}

Statistical analysis was performed with the use of Statistical Package for Social Sciences (SPSS; Chicago, IL, USA) program, version 15. Continuous variables are presented as mean \pm standard deviation (SD) and categorical variables as counts and percentages. The parameters of the patients were compared with non-paired Student $\mathrm{t}$-test. $\mathrm{P}<0.05$ was considered significant.

\section{Results}

Of the 50 patients who were enrolled in the study, 34 (68\%) were males and 16 (32\%) were females. 27 (54\%) patients were in NYHA class II and 23 (46\%) patients were in NYHA class III. On chest X-ray examination, 9, 36, and 5 patients were observed to have Grade 1, 2 and 3 LA enlargements, respectively. The baseline clinical parameters of patients are detailed in Table 1.

On echocardiography, LA volume was found to be $\geq 40 \mathrm{ml}$ in all patients. 11 patients had LA volume of $>60 \mathrm{ml}$. Mild elevated LA volume index was observed in 16 patients, whereas 28 and 6 patients had moderately and severely elevated LA volume index, respectively. Mild, moderate and severe LV dysfunction was found in 34, 11, and 5 patients, respectively (Table 2 ).

Table 3 demonstrates correlation between MR and other echocardiographic parameters like left atrial volume, left atrial volume index and ejection fraction. There was significant correlation of all echocardiographic parameters with the severity of MR.

Correlation between NYHA functional class and other echocardiographic parameters are depicted in Table 4. Ejection fraction and LA volume were significantly correlated with NYHA class presentation $(\mathrm{p}<0.05)$. However, the study does not reveal any significant correlation between functional status of the patient and LA volume index. This may be due to higher body surface area of patients belonging to functional class III.

Correlation between LV function and LA volume was found to be highly significant $(p<0.01)$ (Table 5). A strong negative correlation was seen between them $(r=-0.789)$. 
Table 1. Baseline parameters of the patients.

\begin{tabular}{cc}
\hline Parameters & Patients (N = 50) \\
\hline Age (range, years) & $29-88$ \\
Sex (Male/Female) & $34 / 16$ \\
NYHA functional class & \\
Class II, n (\%) & $27(54 \%)$ \\
Class III, n (\%) & $23(46 \%)$ \\
Duration of symptoms (mean (range), months) & $12(3-36)$ \\
Diabetes, n (\%) & $29(58 \%)$ \\
Atrial fibrillation, n (\%) & $8(16 \%)$ \\
Clinical presentation & \\
Idiopathic cardiomyopathy, n (\%) & $24(48 \%)$ \\
Ischemic cardiomyopathy, n (\%) & $26(52 \%)$ \\
STEMI, n (\%) & $18(36 \%)$ \\
NSTEMI, n (\%) & $8(16 \%)$ \\
Grade 3, n (\%) & $5(10 \%)$ \\
Grade 1, n (\%) & \\
Ghest X-ray and left atrial enlargement & \\
\hline
\end{tabular}

NYHA-New York Heart Association; STEMI-ST Elevation Myocardial Infarction; NSTEMI-Non ST Elevation Myocardial Infarction.

Table 2. Echocardiographic parameters of the patients.

\begin{tabular}{cc}
\hline Parameters & Patients $(\mathrm{N}=50)$ \\
\hline Left atrial volume $(\mathrm{ml})$ & $16(32 \%)$ \\
$40-50, \mathrm{n}(\%)$ & $23(46 \%)$ \\
$50-60, \mathrm{n}(\%)$ & $11(22 \%)$ \\
$>60, \mathrm{n}(\%)$ & \\
Left atrial volume index $\left(\mathrm{ml} / \mathrm{m}^{2}\right)$ & $16(32 \%)$ \\
$28-34, \mathrm{n}(\%)$ & $28(56 \%)$ \\
$34-40, \mathrm{n}(\%)$ & $6(12 \%)$ \\
$>40, \mathrm{n}(\%)$ & \\
Ejection fraction $(\%)$ & $34(68 \%)$ \\
$31-40, \mathrm{n}(\%)$ & $11(22 \%)$ \\
$21-30, \mathrm{n}(\%)$ & $5(10 \%)$ \\
$<20, \mathrm{n}(\%)$ &
\end{tabular}


Table 3. Correlation between mitral regurgitation, left atrial volume, left atrial volume index and ejection fraction.

\begin{tabular}{ccccc}
\hline & Grade 1 & Grade 2 & Grade 3 & p-value \\
\hline Left atrial volume (mean, $\mathrm{ml}$ ) & 48.74 & 57.36 & 69.2 & $<0.01$ \\
Left atrial volume index (mean, $\left.\mathrm{ml} / \mathrm{m}^{2}\right)$ & 30.21 & 33.98 & 40.77 & $<0.01$ \\
Ejection fraction (mean, \%) & 36.59 & 30.19 & 22.14 & $<0.01$ \\
\hline
\end{tabular}

Table 4. Correlation between NYHA functional classes, left atrial volume, left atrial volume index and ejection fraction.

\begin{tabular}{cccc}
\hline & NYHA class II & NYHA class III & p-value \\
\hline Left atrial volume (mean, ml) & 53.60 & 59.00 & $<0.05$ \\
Left atrial volume index (mean, $\mathrm{ml} / \mathrm{m}^{2}$ ) & 32.61 & 34.94 & $\mathrm{NS}$ \\
Ejection fraction (mean, \%) & 33.03 & 29.13 & $<0.05$ \\
\hline
\end{tabular}

NYHA-New York Heart Association; NS-Non Significant.

Table 5. Correlation between left atrial volume, left atrial volume index, ejection fraction, and duration of symptoms.

\begin{tabular}{ccc}
\hline & r-value & p-value \\
\hline Ejection fraction and LA volume & -0.789 & $<0.01$ \\
Ejection fraction and LA volume index & -0.826 & $<0.01$ \\
LA volume index and duration of symptoms & 0.004 & 0.9 \\
\hline
\end{tabular}

LA-Left Atrial.

Similarly, there was a strong inverse correlation between LV function and LA volume index $(\mathrm{r}=-0.826, \mathrm{p}<0.01)$. There was no correlation between LA volume index and duration of symptoms $(r=0.04)$. This may be probably due to patients having asymptomatic LV dysfunction before becoming symptomatic.

\section{Discussion}

The prognosis of patients with dilated cardiomyopathy has been gloomy, with an average survival of two years following diagnosis. In spite of various advancements; this disease still has awful prognosis [12]. The LA volume is a predictor of cardiovascular events in patients with cardiac failure [6] [13] [14]. Moreover, LA volume is associated with the presence of symptoms in such patients [13]. Though LA dilatation is a marker of LV diastolic dysfunction and can also occur secondarily to MR, it has been imprecise about the determinants of LA enlargement in patients with dilated cardiomyopathy [15]. Present study showed that LA remodeling is frequent with dilated cardiomyopathy. LA volume was found to be a powerful marker adding important clinical information. LA volume is mainly determined by degree of LV dilatation, LV function, extent of MR and atrial fibrillation.

Functional MR is a major confounding factor in the hemodynamics of patients with 
LV systolic dysfunction [16] [17]. MR volume is a key determinant of atrial volume [18] which may reflect the severity, duration and prognosis of MR [19]. Present study revealed direct correlation of severity of MR and increment of LA volume.

Literature suggests that LA volume stores information on the history of illness [20] highlighting its duration [3]. But in our study, duration of symptoms does not have any correlation with the degree of left atrial enlargement. This may be due to the fact that sufficient number of patients may be passing through asymptomatic left ventricle dysfunction phase while the LA may be dilating. Moreover, Rossi et al. [6] also showed only a weak correlation with the duration of symptoms and LA size.

In this study, the LA volume and EF were found to have a strong inverse correlation $(\mathrm{r}=-0.789)$. Whereas in a recent study, these were found to be weakly correlated $(\mathrm{r}=$ $-0.36, \mathrm{p}<0.01)$ in patients with non-ischemic dilated cardiomyopathy [15]. Previously, studies [21] had utilized LA size for prediction of disease progression, but their study was based on LA dimension, not LA volume. LA volume is a more sensitive prognostic marker in cardiovascular disease [22], therefore we evaluated the prognostic significance of LA volume index. Various studies have revealed that an increased LA volume index is allied to augmented morbidity and mortality in patients with cardiovascular disease [14] [23] [24]. Moreover, Yang WI et al. [25] have demonstrated lower eventfree survival rates in patients with hypertrophic cardiomyopathy with LA volume indexes $>39 \mathrm{ml} / \mathrm{m}^{2}$ than those with LA volume indexes $\leq 39 \mathrm{ml} / \mathrm{m}^{2}(\mathrm{p}<0.01)$. Thus LA volume and LA volume index depict to be useful echocardiographic predictors of prognosis in patients with dilated cardiomyopathy.

\section{Conclusion}

In light of the results, it can be concluded that there is a strong inverse correlation between left atrial volume and left ventricular function and also between left atrial volume index and left ventricular function. The patients with NYHA class III were having larger left atrial volume than those with NYHA class II. Moreover, the duration of symptoms has no correlation with left atrial volume index.

\section{References}

[1] Kaur, H., Khetarpal, R. and Aggarwal, S. (2013) Dilated Cardiomyopathy: An Anaesthetic Challenge. Journal of Clinical and Diagnostic Research, 7, 1174-1176. http://dx.doi.org/10.7860/jcdr/2013/5390.3069

[2] Lewis, J.F., Webber, J.D., Sutton, L.L., Chesoni, S. and Curry, C.L. (1993) Discordance in Degree of Right and Left Ventricular Dilation in Patients with Dilated Cardiomyopathy: Recognition and Clinical Implications. Journal of the American College of Cardiology, 21, 649-654. http://dx.doi.org/10.1016/0735-1097(93)90097-K

[3] Giannuzzi, P., Temporelli, P.L., Bosimini, E., Silva, P., Imparato, A., Corrà, U., et al. (1996) Independent and Incremental Prognostic Value of Doppler-Derived Mitral Deceleration Time of Early Filling in Both Symptomatic and Asymptomatic Patients with Left Ventricular Dysfunction. Journal of the American College of Cardiology, 28, 383-390.

http://dx.doi.org/10.1016/0735-1097(96)00163-5 
[4] Pinamonti, B., Di Lenarda, A., Sinagra, G., Camerini, F. and Group HMDS (1993) Restrictive Left Ventricular Filling Pattern in Dilated Cardiomyopathy Assessed by Doppler Echocardiography: Clinical, Echocardiographic and Hemodynamic Correlations and Prognostic Implications. Journal of the American College of Cardiology, 22, 808-815. http://dx.doi.org/10.1016/0735-1097(93)90195-7

[5] Quiñones, M.A., Greenberg, B.H., Kopelen, H.A., Koilpillai, C., Limacher, M.C., Shindler, D.M., et al. (2000) Echocardiographic Predictors of Clinical Outcome in Patients with Left Ventricular Dysfunction Enrolled in the SOLVD Registry and Trials: Significance of Left Ventricular Hypertrophy. Journal of the American College of Cardiology, 35, 1237-1244. http://dx.doi.org/10.1016/S0735-1097(00)00511-8

[6] Rossi, A., Cicoira, M., Zanolla, L., Sandrini, R., Golia, G., Zardini, P., et al. (2002) Determinants and Prognostic Value of Left Atrial Volume in Patients with Dilated Cardiomyopathy. Journal of the American College of Cardiology, 40, 1425-1430. http://dx.doi.org/10.1016/S0735-1097(02)02305-7

[7] Rossi, A. and Vassanelli, C. (2005) Left Atrium: No Longer Neglected. Italian Heart Journal: Official Journal of the Italian Federation of Cardiology, 6, 881-885.

[8] Lester, S.J., Ryan, E.W., Schiller, N.B. and Foster, E. (1999) Best Method in Clinical Practice and in Research Studies to Determine Left Atrial Size. The American Journal of Cardiology, 84, 829-832. http://dx.doi.org/10.1016/S0735-1097(02)02305-7

[9] Benjamin, E.J., D’Agostino, R.B., Belanger, A.J., Wolf, P.A. and Levy, D. (1995) Left Atrial Size and the Risk of Stroke and Death: The Framingham Heart Study. Circulation, 92, 835841. http://dx.doi.org/10.1161/01.CIR.92.4.835

[10] Jiamsripong, P., Honda, T., Reuss, C.S., Hurst, R.T., Chaliki, H.P., Grill, D.E., et al. (2008) Three Methods for Evaluation of Left Atrial Volume. European Heart Journal-Cardiovascular Imaging, 9, 351-355.

[11] Lang, R.M., Bierig, M., Devereux, R.B., Flachskampf, F.A., Foster, E., Pellikka, P.A., et al. (2005) Recommendations for Chamber Quantification: A Report from the American Society of Echocardiography's Guidelines and Standards Committee and the Chamber Quantification Writing Group, Developed in Conjunction with the European Association of Echocardiography, a Branch of the European Society of Cardiology. Journal of the American Society of Echocardiography, 18, 1440-1463.

http://dx.doi.org/10.1016/j.echo.2005.10.005

[12] Ferreira, F., Galrinho, A., Soares, R., Branco, L., Abreu, J., Feliciano, J., et al. (2013) Prognostic Value of Left Atrial Volume in Patients with Dilated Cardiomyopathy. Revista Portuguesa de Cardiologia (English Edition), 32, 865-872.

http://dx.doi.org/10.1016/j.repce.2013.10.028

[13] Acarturk, E., Koc, M., Bozkurt, A. and Unal, I. (2008) Left Atrial Size May Predict Exercise Capacity and Cardiovascular Events. Texas Heart Institute Journal, 35, 136-143.

[14] Nunes, M.C.P., Barbosa, M.M., Ribeiro, A.L.P., Colosimo, E.A. and Rocha, M.O. (2009) Left Atrial Volume Provides Independent Prognostic Value in Patients with Chagas Cardiomyopathy. Journal of the American Society of Echocardiography, 22, 82-88. http://dx.doi.org/10.1016/j.echo.2008.11.015

[15] Mancuso, F.J.N., Moisés, V.A., Almeida, D.R., Poyares, D., Storti, L.J., Oliveira, W.A., et al. (2015) Left Atrial Volume Determinants in Patients with Non-Ischemic Dilated Cardiomyopathy. Arquivos Brasileiros de Cardiologia, 105, 65-70.

[16] Enriquez-Sarano, M., Rossi, A., Seward, J.B., Bailey, K.R. and Tajik, A.J. (1997) Determinants of Pulmonary Hypertension in Left Ventricular Dysfunction. Journal of the American College of Cardiology, 29, 153-159. http://dx.doi.org/10.1016/S0735-1097(96)00436-6 
[17] Rossi, A., Cicoira, M., Golia, G., Anselmi, M. and Zardini, P. (2001) Mitral Regurgitation and Left Ventricular Diastolic Dysfunction Similarly Affect Mitral and Pulmonary Vein Flow Doppler Parameters: The Advantage of End-Diastolic Markers. Journal of the American Society of Echocardiography, 14, 562-568. http://dx.doi.org/10.1067/mje.2001.111475

[18] Rossi, A., Golia, G., Gasparini, G., Prioli, M.A., Anselmi, M. and Zardini, P. (1999) Left Atrial Filling Volume Can Be Used to Reliably Estimate the Regurgitant Volume in Mitral Regurgitation. Journal of the American College of Cardiology, 33, 212-217. http://dx.doi.org/10.1016/S0735-1097(98)00545-2

[19] Reed, D., Abbott, R.D., Smucker, M.L. and Kaul, S. (1991) Prediction of Outcome after Mitral Valve Replacement in Patients with Symptomatic Chronic Mitral Regurgitation. The Importance of Left Atrial Size. Circulation, 84, 23-34. http://dx.doi.org/10.1161/01.CIR.84.1.23

[20] Hoit, B.D., Shao, Y., Tsai, L.-M., Patel, R., Gabel, M. and Walsh, R.A. (1993) Altered Left Atrial Compliance after Atrial Appendectomy. Influence on Left Atrial and Ventricular Filling. Circulation Research, 72, 167-175. http://dx.doi.org/10.1161/01.RES.72.1.167

[21] Nistri, S., Olivotto, I., Betocchi, S., Losi, M.A., Valsecchi, G., Pinamonti, B., et al. (2006) Prognostic Significance of Left Atrial Size in Patients with Hypertrophic Cardiomyopathy (From the Italian Registry for Hypertrophic Cardiomyopathy). The American Journal of Cardiology, 98, 960-965. http://dx.doi.org/10.1016/j.amjcard.2006.05.013

[22] Tsang, T.S., Abhayaratna, W.P., Barnes, M.E., Miyasaka, Y., Gersh, B.J., Bailey, K.R., et al. (2006) Prediction of Cardiovascular Outcomes with Left Atrial Size: Is Volume Superior to Area or Diameter? Journal of the American College of Cardiology, 47, 1018-1023. http://dx.doi.org/10.1016/j.jacc.2005.08.077

[23] Beinart, R., Boyko, V., Schwammenthal, E., Kuperstein, R., Sagie, A., Hod, H., et al. (2004) Long-Term Prognostic Significance of Left Atrial Volume in Acute Myocardial Infarction. Journal of the American College of Cardiology, 44, 327-334. http://dx.doi.org/10.1016/j.jacc.2004.03.062

[24] Tsang, T.S., Barnes, M.E., Gersh, B.J., Takemoto, Y., Rosales, A.G., Bailey, K.R., et al. (2003) Prediction of Risk for First Age-Related Cardiovascular Events in an Elderly Population: The Incremental Value of Echocardiography. Journal of the American College of Cardiolo$g y$, 42, 1199-1205. http://dx.doi.org/10.1016/S0735-1097(03)00943-4

[25] Yang, W.-I., Shim, C.Y., Kim, Y.J., Kim, S.-A., Rhee, S.J., Choi, E.-Y., et al. (2009) Left Atrial Volume Index: A Predictor of Adverse Outcome in Patients with Hypertrophic Cardiomyopathy. Journal of the American Society of Echocardiography, 22, 1338-1343.

http://dx.doi.org/10.1016/j.echo.2009.09.016 
Submit or recommend next manuscript to SCIRP and we will provide best service for you:

Accepting pre-submission inquiries through Email, Facebook, LinkedIn, Twitter, etc.

A wide selection of journals (inclusive of 9 subjects, more than 200 journals)

Providing 24-hour high-quality service

User-friendly online submission system

Fair and swift peer-review system

Efficient typesetting and proofreading procedure

Display of the result of downloads and visits, as well as the number of cited articles

Maximum dissemination of your research work

Submit your manuscript at: http://papersubmission.scirp.org/

Or contactwjcd@scirp.org 